\title{
Cryogenic Blackbody Calibrations at the National Institute of Standards and Technology Low Background Infrared Calibration Facility
}

\begin{tabular}{lll}
\hline Volume 99 & Number 1 & January-February 1994 \\
\hline
\end{tabular}

R. U. Datla, M. C. Croarkin, and A. C. Parr

National Institute of Standards and Technology, Gaithersburg, MD 20899-0001
The Low Background Infrarcd Calibration Facility (LBIR) at the National Institute of Standards and Technology has been in operation for calihration measurements of the radiant power emitted from intrared radiation (IR) sources, such as cryugenic blackbodies, for more than 2 years. The IR sources are sent to NIST by customers from industry, government, and university laboratories. An absolute cryogenic radiometer is used as the standard detector to measure the total radiant power at its aperture. The low background is provided by a closed cycle helium refrigeration system that maintains the inner parts of the calibration chanber at $20 \mathrm{~K}$. The radiance temperature of the blackbody is deduced from the measured power and compared with the blackbody temperature sensor data. The calthration procedures and data analysis arc illustrated using the measurements of a typical blackbody.

Key words: blackbody calibrations; cryogenic blackbodies; cryogenic radiometer, electrical substitution radiometry, low background infrased radiation calibrations; radiometry.

Accepted: November 19, 1993

\section{Introduction}

The national need to establish a primaty standard reference for calibrating infrared sensors led to the establishment, in 1989, of the Low Background Infrared Calibration Facility (LBIR) at the National Institute of Standards and Technology. This facility has been serving a variety of users from industry and government laboratories by providing calibrations of cryogenic blackbody sources. These sources are used by the customer for calibrations of their infrared sensor systems. An absolute cryogenic radiometer (ACR) of the electrical substitution type has been developed as the standard reference detector for the LBIR calibrations. The ACR measures the total radiant power incident on its precision aperture. Its operating range for radjant power measurements is $20 \mathrm{nW}$ to $100 \mu \mathrm{W}$ with an expanded uncertainly of $\pm 1 \%$ (95\% confidence level). The physical description of the ACR and its characterization as an absolute detector for tadiant power measurements have been described in Ref. [1]. The LBIR chamber is shown in Fig. 1.

The cylindrical vacuum tank housing the ACR detector and the customer blackbody source is made of stainless steel and is $152 \mathrm{~cm}$ long and $60 \mathrm{~cm}$ in diameter. Two shields made of copper (shown in the cutaway portion of Fig. 1) separated by a 2.54 $\mathrm{cm}$ gap are cooled by a helium refrigerator which circulates cooled helium gas (15 K) through copper lines vacuum brazed to these shields. The inner shield operates at $20 \mathrm{~K}$ and provides the low thermal radiation background inside the chamber. The inner surface of the inner shield has a highly 


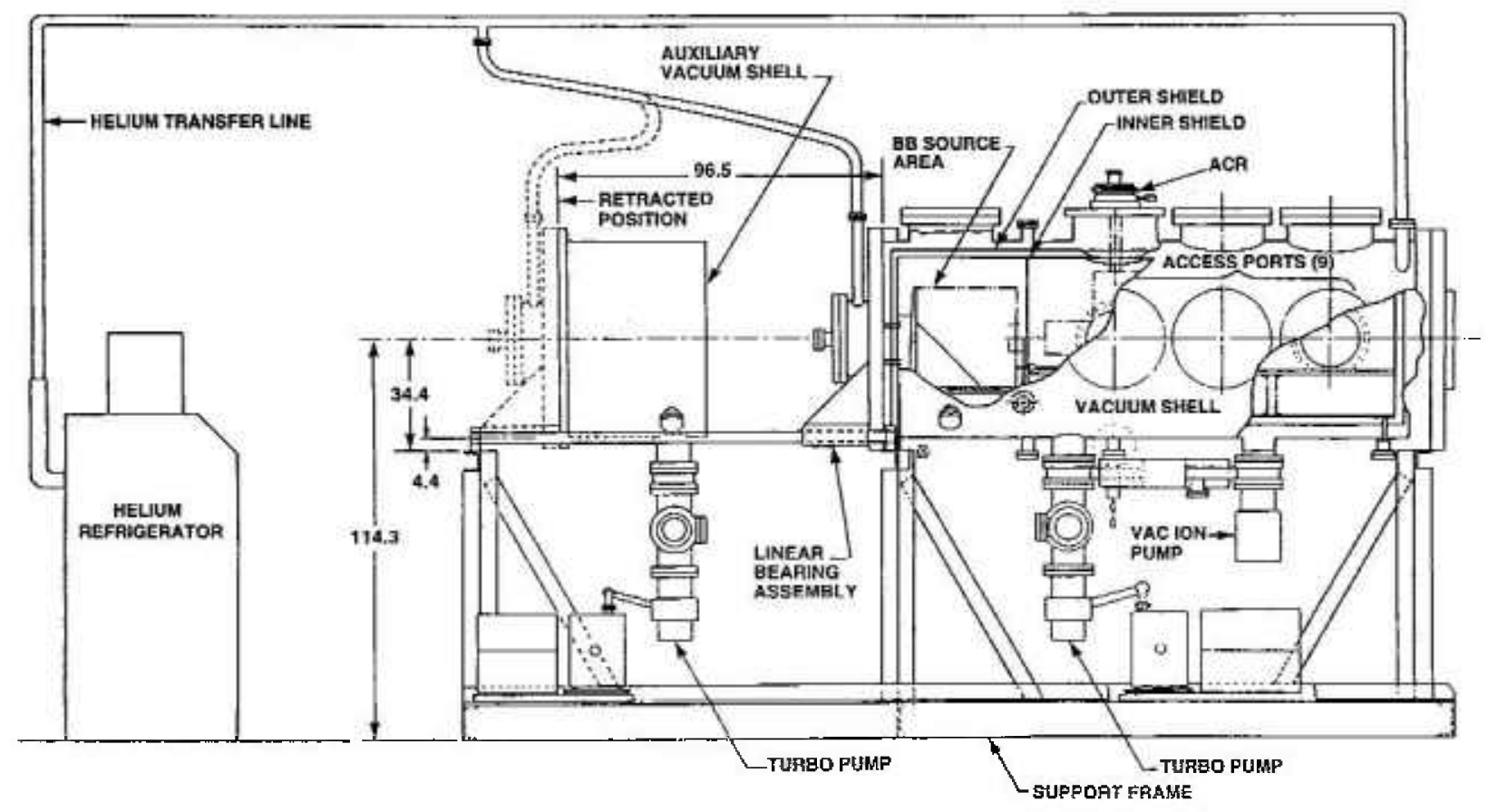

Fig. 1. LBIR chamber with partial cutaway showing the major features of the apparates.

absorbent black coating of IITRI MH-2200 paint' to reduce scattered radiation. The ACR can be placed in any of the three ports of the LBIR chamber, which are located at distances of approximately $30 \mathrm{~cm}, 65 \mathrm{~cm}$, and $100 \mathrm{~cm}$ from the blackbody source under test. The placement of the ACR can be chosen so that the radiant power at its aperture is in the ACR measurement range. $A$ complete description of the facility can be found in a previous publication [3].

The general requirements for blackbody calibrations are described in Sec. 2 of this article. The procedures for handling the cryogenics of the calibration setup and the procedures adopted for measurements and analysis are described in Sec. 3. A recent blackbody calibration illustrates the procedures. The blackbody in question has two sensors and is referred to as BB in this paper.

\section{Calibration Requirements}

Calibration requirements fall into two categories: 1) needs established by the customer and 2) needs of the NIST LBIR facility. A typical

\footnotetext{
${ }^{1}$ Certain commercial equipment, instruments, or materials are identified in this paper to specify adequately the experimental procedure. Such identification does not imply recommendation or endorsement by the National Institute of Standards and Technology, nor does it imply that the materiats or equipment identified are necessarily the best avaihable for the purpose. 4
}

customer requirement for the $\mathrm{BB}$ is as follows: 1) measure the radiant power at the ACR aperture for the blackbody temperature range of $200 \mathrm{~K}$ to $400 \mathrm{~K}$ in increments of $25 \mathrm{~K}$ for the source aperture diameter of $650 \mu \mathrm{m}$ and 2) calibrate the temperature sensors of the source by comparing with the deduced radiance temperature. NIST issues guidelines to the customer for preparing the blackbody source to conform to the vacuum and allowable contaminant level specifications of the LBIR chamber. The NIST requirement specifies that the partial pressure of hydrocarbons (beyond approximately $45 u$ ) should not exceed $1.33 \times 10^{-8} \mathrm{~Pa}$ for a total base pressure of $1.33 \times 10^{-6} \mathrm{~Pa}$. Other requirements are described in detail in Ref. [3]. NIST also supplies the customer with a mounting plate and guidelines for installing the plate on the blackbody source [3].

\section{Calibration Procedures}

\subsection{Cryogenic Apparatus and Preparation for Measurements}

The blackbody is integrated into the LBIR chamber after testing its vacuum integrity. Cryoconditioning of the LBIR chamber follows with the inner shield of the chamber being cooled to approximately $20 \mathrm{~K}$ and the outer shield being cooled to approximately $40 \mathrm{~K}$. The blackbody mounting 
shelf and the main chamber have separate cold helium feeds with flow control valves to allow diversion of additional coolant to the blackbody, if needed. The cryoshields have several silicon diode thermometers attached at various points. These thermometers are monitored during calibration to ensure stability of the IR environment.

In order to provide a steady background flux for the ACR, a copper disk separates the blackbody chamber from the ACR chamber. This disk, called the isothermal plate, is moderately thermally insulated from the inner shield. The isothermal plate is fitted with an aperture that blocks the background radiation from the blackbody chamber without limiting the field of view of the ACR aperture. Complete isolation of the ACR chamber is achieved, if necessary, by a shutter in front of the isothermal plate that can be operated by remote control. The shutter is thermally anchored to the isothermal plate with a flexible copper braid. The temperature of the isothermal plate and shutter are monitored by three precision silicon diode thermometers. The isothermal plate is controlled to $0.05 \mathrm{~K}$ by using an integral heating element and the temperature is held at $22 \mathrm{~K}$.

\subsection{Measurements}

Figure 2 shows the calibration setup inside the LBIR chamber. Blackbody sensor data and radiant power data are collected at each blackbody temperature and aperture setting specified by the customer. Data are collected and recorded at approximately one second intervals for a period of three minutes at each setting. These data form the

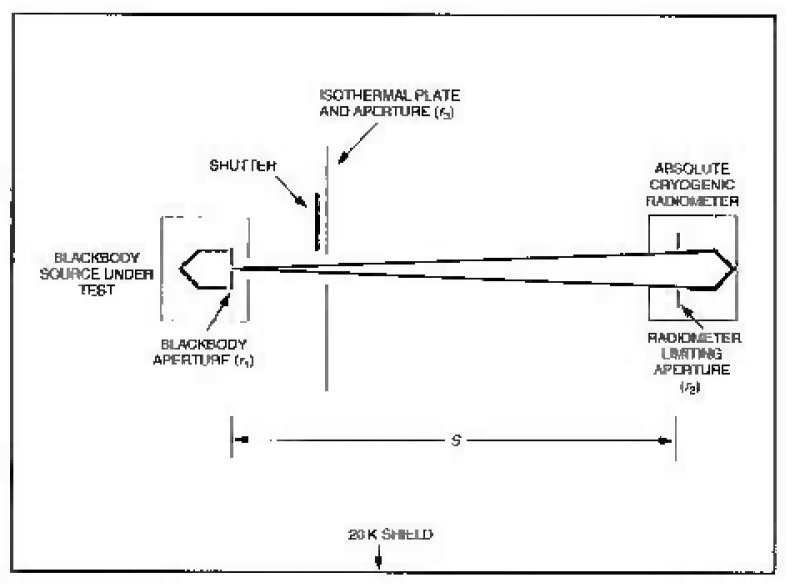

Fig. 2. Blackbody calibration setup inside the LBIR chamber. basis for estimating the repeatability of the instrumentation. Cryogenic preparation of the ACR and the complete calibration sequence are repeated on three different days to test the reproducibility of the entire measurement system.

3.2.1 Blackbody Temperature Sensors The blackbody temperature is generally measured by platinum resistance thermometers (PRTs) mounted on the blackbody core. Voltages actoss the PRTs measured by a multimeter, and currents supplied by a constant current source are converted to resistance values using Ohm's law. The resistances are converted to temperature values if the customer provides data on the calibration of the PRT sensors. Nominal settings on the external temperature control electronics of the $\mathrm{BB}$ and measured temperatures for the BB sensors are shown in columns 1, 2, and 4 of Table 1. Experimental standard deviations from the $1 \mathrm{~s}$ repetitions at each setting on each day are shown in columns 3 and 5 of the same table.

3.2.2 Radiant Power The radiant power at the ACR aperture is measured as follows: The radiation from the blackbody is blocked from the $A C R$ receiver by using the shutoff position on the blackbody aperture wheel (if available). The electrical heater power to the ACR receiver is set to a value higher (preferably $20 \%$ to $30 \%$ ) than the expected radiant power from the blackbody so that the temperature controller servo (ac bridge) can maintain a constant temperature at the ACR cone by varying the amount of electrical power. Preliminary estimates of radiant power at the ACR aperture are made using the Stefan-Boltzmann law and the approximate distance between the ACR aperture and the blackbody aperture. After the ac bridge is balanced, the ACR is allowed to receive the blackbody radiation by turning the aperture wheel to a chosen aperture position. If the customer blackbody is equipped with a fixed aperture, the $152 \mathrm{~mm}$ ( 6 in) shutter in front of the isothermal plate is used for blocking the blackbody radiation. The difference between the initial electrical power setting with the shutter closed and the final electrical power setting with the shutter open is the radiant power at the ACR aperture. Data is taken continuously at one second intervals for at least 3 min with the shutter open, in order to determine the repeatability of the instrumentation.

3.2.3 Geometry The measurement of the radius of the blackbody aperture, $r_{1}$ (see Fig. 2), corrected for thermal contraction at $20 \mathrm{~K}$, is supplied by the customer. The radius of the ACR aperture, $r_{2}$, has been measured by the Precision Engineering 
Table 1. Experimental datn

\begin{tabular}{|c|c|c|c|c|c|c|c|}
\hline $\begin{array}{l}\text { Nominal } \\
\text { (K) }\end{array}$ & $\begin{array}{c}\text { Sensor } 1 \\
(\mathrm{~K})\end{array}$ & $\begin{array}{l}\text { Std. dev. } \\
\text { (K) }\end{array}$ & $\begin{array}{c}\text { Sensor } 2 \\
\text { (K) }\end{array}$ & $\begin{array}{l}\text { Std. dev. } \\
\text { (K) }\end{array}$ & $\begin{array}{l}\text { Measured } \\
\text { power(nW) }\end{array}$ & $\begin{array}{c}\text { Average } \\
\text { power(nW) }\end{array}$ & $\begin{array}{l}\text { Std, dev, of } \\
\text { average (nW) }\end{array}$ \\
\hline \multirow[t]{3}{*}{200} & 199.897 & 0.002 & 199.281 & 0.002 & 71.9 & 71.5 & $0.5(0.6 \%)$ \\
\hline & 199.874 & 0.005 & 199.332 & 0.005 & 72.0 & & \\
\hline & 199.947 & 0.002 & 199.328 & 0.003 & 70.6 & & \\
\hline \multirow[t]{3}{*}{225} & 224.780 & 0.003 & 224.266 & 0.004 & 113.5 & 113.3 & $0.1(0.1 \%)$ \\
\hline & 224.728 & 0.003 & 224.276 & 0.006 & 113.4 & & \\
\hline & 224.823 & 0.004 & 224.306 & 0.004 & 113.0 & & \\
\hline \multirow[t]{3}{*}{250} & 249.662 & 0.004 & 249.268 & 0.004 & 171.3 & 172.0 & $0.4(0.2 \%)$ \\
\hline & 249639 & 0.007 & 249.288 & 0.008 & 172.6 & & \\
\hline & 249.733 & 0.005 & 249.322 & 0.004 & 172.2 & & \\
\hline \multirow[t]{3}{*}{275} & 274.685 & 0.003 & 274.408 & 0.002 & 252.6 & 252.5 & $0.2(0.1 \%)$ \\
\hline & 274.644 & 0.006 & 274.394 & 0.007 & 252.2 & & \\
\hline & 274.719 & 0.006 & 274.443 & 0.004 & 252.8 & & \\
\hline \multirow[t]{3}{*}{300} & 299.531 & 0.007 & 299.329 & 0.007 & 358.4 & 358.0 & $0.4(0.1 \%)$ \\
\hline & 299.521 & 0.003 & 299.346 & 0.004 & 357.3 & & \\
\hline & 299,588 & 0.005 & 299.389 & 0.004 & 358.4 & & \\
\hline \multirow[t]{3}{*}{325} & 324.412 & 0.006 & 324.346 & 0.006 & 497.6 & 494.6 & $1.4(0.3 \%)$ \\
\hline & 324.457 & 0.005 & 324.375 & 0.005 & 492.8 & & \\
\hline & 324.446 & 0.003 & 324.379 & 0.004 & 493.4 & & \\
\hline \multirow[t]{3}{*}{350} & 349.306 & 0.003 & 349.378 & 0.003 & 665.8 & 664.8 & $0.8(0.1 \%)$ \\
\hline & 349.337 & 0.008 & 349.395 & 0.011 & 663.7 & & \\
\hline & 349.445 & 0.006 & 349.479 & 0.006 & 664.8 & & \\
\hline \multirow[t]{3}{*}{375} & 374.047 & 0.005 & 374.284 & 0.005 & 882.2 & 878.3 & $2.0(0.2 \%)$ \\
\hline & 374,069 & 0.003 & 374.292 & 0.003 & 875.7 & & \\
\hline & 374.171 & 0.006 & 374.377 & 0.007 & 877.0 & & \\
\hline \multirow[t]{3}{*}{400} & 399.026 & 0.005 & 399.362 & 0.005 & 11380 & 1137.1 & $1.3(0.1 \%)$ \\
\hline & 399.056 & 0.004 & 399.379 & 0.004 & 1134,6 & & \\
\hline & 399.131 & 0.004 & 399.444 & 0.003 & 1138.8 & & \\
\hline
\end{tabular}

Division at NIST at room temperature in three different orientations. The average radius is corrected for thermal contraction as explained in Ref. [1].

The distance, $S$, between the blackbody aperture and the ACR limiting (precision) aperture is measured in two parts. The user measures the distance between the blackbody aperture and the front surface of a reference tab on the blackbody mounting plate as required by NIST [3], and NIST personnel measure the distance from the front surface of the tab to the ACR aperture. The chamber measurement is assisted by a Kaman proximity sensor [4] located internally to determine the final location of the reference tab to the ACR aperture before the chamber is evacuated. The measurements are made at ambient temperature and corrected for thermal contraction due to cooling of the chamber and the $A C R$ to $20 \mathrm{~K}$ and $2 \mathrm{~K}$, respectively. The radius of the aperture in the isothermal plate, $r_{3}$, shown in Fig. 2, is chosen to limit the background flux from the blackbody front surface. However, it will allow the full cone of light from the blackbody aperture to reach the ACR aperture. The geometrical measurements for the $\mathrm{BB}$ are given in Table 2.

3.2.4 Radiance Temperature The following equation deduced from the Stefan-Boltzmann law is used to convert the radiant power to radiance temperature, $T$ :

$$
T=\left[\frac{P}{F_{1} A_{1} \sigma_{M}}\right]^{1 / 4}
$$

where

$$
\begin{aligned}
& F_{\mathrm{k}}=(1 / 2)\left[z-\left[z^{2}-4 x^{2} \cdot y^{2}\right]^{1 / 2}\right], \\
& x=\frac{r_{2}}{S}, y=\frac{S}{r_{1}}, z=1+\left(1+x^{2}\right) y^{2},
\end{aligned}
$$


Table 2. Geometric data for $\mathbf{B B}$ calibration

\begin{tabular}{|c|c|c|c|c|}
\hline & & & $\begin{array}{l}\text { Meas. } \\
\text { value }\end{array}$ & $\begin{array}{l}\text { Std. dev. } \\
\text { mean }\end{array}$ \\
\hline \multirow{5}{*}{$\begin{array}{l}1 . \\
2 . \\
3 .\end{array}$} & \multirow{3}{*}{\multicolumn{2}{|c|}{$\begin{array}{l}\text { Radius }\left(r_{2}\right) \text { of the ACR apertuse at } 2.2 \mathrm{~K} \\
\text { Distance between the apertures }(S) \\
\text { BB aperture radius }\left(r_{1}\right) \text { : }\end{array}$}} & $1.4971 \mathrm{~cm}$ & $5 \times 10^{-5} \mathrm{~cm}$ \\
\hline & & & $30.77 \mathrm{~cm}$ & $0.042 \mathrm{~cm}$ \\
\hline & & & & \\
\hline & $\begin{array}{c}\text { Nominal } \\
\text { mm }\end{array}$ & $\begin{array}{l}\text { Measured at } \\
\text { ambient } \\
\text { mm }\end{array}$ & $\begin{array}{l}\text { Deduced } \\
20 \mathrm{~K} \\
\mathrm{~mm}\end{array}$ & $\begin{array}{c}\text { Std. dev, mear } \\
\text { min }\end{array}$ \\
\hline & 0.325 & 0.3251 & 0.3244 & 0.0013 \\
\hline
\end{tabular}

and $A_{1}=\pi r_{1}^{2}$ is the area of the blackbody aperture; $P$ is the radiant power and $o_{M}$ is the Stefan-Boltzmann constant, and equal to $5.67051 \times 10^{-8} \mathrm{~W} \mathrm{~m}^{-2}$ $\mathrm{K}^{-4}$. The expression for the configuration factor, $F_{1}$, given above is taken from Ref. [5] and to a first order approximation reduces to $\pi_{2}^{2} / S^{2}$. The quantities $r_{1}, r_{2,}$ and $\mathrm{S}$ have already been defined, and their measured values at room temperature are adjusted to cryogenic temperatures using the standard reference data for contraction of materials [6].

\subsection{Analysis}

3.3.I Diffraction Correction It has been established in the literature $[7,8]$ that the radiation from the blackbody incident at the ACR aperture will not be solely determined according to geometrical optics because of diffraction effects at both limiting and nonlimiting apertures in the beam path. Therefore, diffraction losses at each one of the apertures in the beam path are estimated by using the procedures published in Refs. [7] and [8]. The measured radiant power values and the deduced radiance temperatures are corrected for the total diffraction loss which is a product of the fractional losses at each aperture in the beam path. The calculated correction factors $(\Delta P / P)$ given as a percentage of the measured power values for the $B B$ are listed in Table 3 for various temperatures. The corresponding correction factor $(\Delta T / T)$ for the radiance temperature is approximately $1 / 4$ of the correction $(\triangle P / P)$ for the radiant power.
Table 3. Calculated diffraction correction $(\Delta P)$ given as a percentage of the measured radiant power $(P)$. Systematic tucertanty (Type B) in the correction the to approximations in the calculations is $\pm 10 \%$ of $\triangle P / P$.

\begin{tabular}{lcc}
\hline \hline $\begin{array}{l}\text { Nominal } \\
\text { blackbody } \\
\text { temp. (K) }\end{array}$ & $\begin{array}{c}\text { Diff. cotr. } \\
\Delta P / P\end{array}$ & Uncer. (1 $\sigma)$ \\
\hline 200 & & \\
225 & $1.3 \%$ & $\pm 0.13 \%$ \\
250 & $1.2 \%$ & $\pm 0.12 \%$ \\
275 & $1.1 \%$ & $\pm 0.11 \%$ \\
300 & $1.0 \%$ & $\pm 0.1 \%$ \\
325 & $0.9 \%$ & $\pm 0.09 \%$ \\
350 & $0.8 \%$ & $\pm 0.08 \%$ \\
375 & $0.8 \%$ & $\pm 0.08 \%$ \\
400 & $0.7 \%$ & $\pm 0.07 \%$ \\
\hline. & $0.7 \%$ & $\pm 0.07 \%$ \\
\hline
\end{tabular}

3.3.2 Measurement Uncertainties The uncertainties in the measurements are analyzed according to guidelines under development by the International Organization for Standardization (ISO) [9]. Uncertainties are caused by either systematic or random effects. Uncertainties from systematic effects (here after called systematic uncertainties for simplicity) are of the following types for this experiment: 1) uncertainties in theoretical corrections applied to measured data such as the uncertainties associated with the diffraction corrections; 2) uncertainties in the measured values of parameters that remain constant during the calibration. Examples of such uncertainties are the parameters that characterize the ACR response [1] which do not change during the ACR power 
measurements. These uncertainties are Type B uncertainties according to Ref. [9] Subclause 3.3.3. Uncertainties from random effects (hereafter called random uncernainties for simplicity) arise from the statistical variation in the measurements during the calibration experiment. This type of variation is inherent in the blackbody PRT sensor measurements of temperature and the ACR measurements of radiant power during the calibration experiment. These are Type A uncertainties [9].

\section{Uncertainty in Radiant Power}

The uncertainty in the ACR measurement of the radiant power is analyzed as follows: For each nominal temperature, radiant power data $\left(P_{i}\right)$ are collected every 1-1/2 s for approximately $3 \mathrm{~min}$, leading to approximately 120 data points. An average, $\bar{P}$, and standard deviation, $s_{\mathrm{ph}}$, are calculated from this data. The standard deviation, $s_{\text {rpt, }}$ is a measure of the repeatability of the measurements in each set, and in general, the ACR data show very good repeatability. The measurement process is repeated three different times to estimate a standard deviation, $s_{\text {rpr }}$, for reproducibility. The average over the three runs is calculated as:

$$
\overline{\bar{P}}=\frac{1}{3} \sum_{j=1}^{3} \vec{P}_{j}
$$

a standard deviation $\left(s_{1}\right)$ is calculated from

$$
s_{\mathrm{s}}^{2}=\sum_{j=1}^{3}\left(\bar{P}_{j}-\overline{\bar{P}}\right)^{2} / 2 .
$$

The standard deviation $\left(s_{i}\right)$ is a measure of both repeatability and reproducibility of measurements [10] according to

$$
s_{\mathrm{t}}^{2} \approx s_{p \mathrm{pr}}^{2}+s_{\mathrm{p} 1}^{2} / 120
$$

Although more repetitions of the entire measurement process would be desirable for better statistics, time constraints limit the number of repetitions. The radiant powers, $\bar{P}_{j}$, and the average powers, $\bar{P}$, for the $B B$ are given in columns 6 and 7 , respectively, of Table 1 . The standard deviations of the means, $s / \sqrt{3}$, are given in column 8 .

Two sources of systematic uncertainty are evaluated as Type $B$ following Ref. [9]. The standard uncertainty (i.e., $1 \sigma$ level) in the diffraction correction to the measured radiant power is based on diffraction theory used to calculate the correction. This standard uncertainty is estimated to be $\pm 10 \%[7,8]$ of the calculated correction based on scientific judgment (Sec. 4.6 Ref. [11]), as shown in column 3 of Table 3 for the BB. The standard uncertainty in the characterization of the tadiometer as given in Ref. [1] is $0.12 \%$ of the measured radiant power. The standard uncertainty due to systematic effects is then the square root of the sum of the squares of the two components.

The random and systematic uncertainties are listed separately in the calibration report. The combined standard uncertainty $\left(u_{c}\right)$ is reported as the square root of the sum of the squares of all of the components. However, it should be noted that other methods of combining components of uncertainty from systematic and random effects are in practice for calculating the total uncertainty [12]. Therefore, all components of uncertainty are listed to give the customer the choice of using an alternative method.

The radiant power data from Table 1 after correction for diffraction loss are shown in column 6 of Table 4. The uncertainty components associated with the average power are shown in columns 7 and 8 , and the combined standard uncertainty, $u_{c}$ is given in column 9.

\section{Uncertainty in the Blackbody Sensor Data}

The Type A (random) uncertainty in the blackbody PRT sensor data is analyzed as follows: The PRT sensor data are collected in conjunction with the ACR power measurements. In general, the standard deviations for the PRT sensor data are homogeneous and negligibly small. Repeated sets of data are averaged to obtain the mean and the corresponding standard deviation analogously to the method discussed earlier for the ACR power measurements. The mean temperature values of the BB with associated standard deviations are shown in columns 2 through 5 of Table 4 .

\section{Radiance Temperature and Calibration Uncertainty}

The final radiance temperatures for the calibration report are obtained by the least-squares analysis of temperatures, $T_{i j}(i=1, \ldots, n ; j=1, \ldots, 3)$, deduced from Eq. (1), as a function of blackbody sensor readings, $X_{i j}\left(i=1, \ldots, n_{j} j=1, \ldots, 3\right)$, for each aperture setting.

In order to evaluate a confidence band for the variability of the calibration curve, the following statistical procedure is adopted. The calibration equation is assumed to follow the model

$$
\begin{gathered}
T_{i j}=a_{0}+a_{1} X_{i j}+a_{2} X_{i j}^{2}+a_{3} X_{i j}^{3}+\ldots+ \\
a_{k} X_{i j}^{k}+\epsilon_{i j},
\end{gathered}
$$


Table 4. Average blackboty sensor data and radiant puwer cortected for diffraction effects at the ACR aperture for the BB

\begin{tabular}{|c|c|c|c|c|c|c|c|c|}
\hline $\begin{array}{l}\text { Nominal } \\
\text { (K) }\end{array}$ & $\begin{array}{c}\text { Sensor } 1 \\
\text { data } \\
\text { (K) }\end{array}$ & $\begin{array}{c}\text { Sid. dcv, } \\
\text { (K) }\end{array}$ & $\begin{array}{c}\text { Sensor } 2 \\
\text { data } \\
\text { (K) }\end{array}$ & $\begin{array}{c}\text { Std. dev. } \\
\text { (K) }\end{array}$ & $\begin{array}{c}\text { Average } \\
\text { power } \\
\text { nW }\end{array}$ & $\begin{array}{l}\text { Syst. } \\
\text { uncer. } \\
\pi W\end{array}$ & $\begin{array}{c}\text { Random } \\
\text { uncer. } \\
\text { nW }\end{array}$ & $\begin{array}{c}\text { Comb. } \\
\text { uncer. } \\
u_{\varepsilon}(1 \sigma) \\
\text { nW }\end{array}$ \\
\hline 200 & 199,906 & 0.003 & 199313 & 0.003 & 72.4 & 0.1 & 0.5 & $0.5(0.6 \%)$ \\
\hline 225 & 224.777 & 0.003 & 224.282 & 0.004 & 114.6 & 0.2 & 0.1 & $0.2(0.2 \%)$ \\
\hline 250 & 249.678 & 0.005 & 249.293 & 0.005 & 173.9 & 0.3 & 0.4 & $0.5(0.3 \%)$ \\
\hline 275 & 274.683 & 0.005 & 274.415 & 0.005 & 255.0 & 0.4 & 0.2 & $0.5(0.2 \%)$ \\
\hline 300 & 299.547 & 0.005 & 299355 & 0.005 & 361.2 & 0.5 & 0.4 & $0.6(0.2 \%)$ \\
\hline 325 & 324,429 & 0.005 & $324-367$ & 0.005 & 498,6 & 0.7 & 1.4 & $1.6(0.3 \%)$ \\
\hline 350 & 349.362 & 0.006 & 349.429 & 0,007 & 669.8 & 1.0 & 0.8 & $1.3(0.2 \%)$ \\
\hline 375 & 374.120 & 0.005 & 374.331 & 0.005 & 884.5 & 1.2 & 2.0 & $2.3(0.3 \%)$ \\
\hline 400 & 399.071 & 0.005 & 399.395 & 0.004 & 1144.6 & 1.6 & 1.3 & $2.1(0.2 \%)$ \\
\hline
\end{tabular}

where $a_{0,} \ldots, a_{k}$ are to be estimated, and $\epsilon_{i j}$, the random errors associated with the measurements $T_{i j}$, are assumed to be independent with heterogeneous variances $\sigma_{i j}^{2}$. The $\sigma_{i j}$ are estimated by $s_{i j}$ from approximately 120 data points for each nun. Weighted least squares [13] accounts for the heterogeneity of variances where the weights, $w_{i}$, are calculated from the empirical variances by

$$
\boldsymbol{w}_{i j}=1 / \mathrm{s}_{i j}^{2} .
$$

The standard deviations associated with the $T_{i j}$ are an order of magnitude larger than the standard deviations associated with the $X_{i}$ data, and, therefore, random uncertainties associated with the measurements $X_{i j}$ are assumed to be negligible for the purpose of the least squares analysis. The degree, $k$, for the polynomial in Eq. (6) is determined by a goodness-of-fit test [14] which compares the agreement among groups of three runs with the overall fit to the data. The lowest degree polynomial which satisfies the goodness-of-fit criterion is taken as the calibration curve.

Given a future blackbody sensor setting, $X_{h}$, its calibrated radiance temperature value is given by

$$
T_{\mathrm{h}}=a_{0}^{\prime}+a_{1}^{\prime} X_{\hbar}+a_{2}^{\prime} X_{h}^{2}+a_{3}^{\prime} X_{h}^{*}+\ldots+a_{k}^{\prime} X_{h}^{k},
$$

where $a_{0}^{\prime}, \ldots, a_{k}^{\prime}$ are least-squares estimates from calibration data. The random component of uncer- tainty associated with the predicted value is computed as

$$
\begin{gathered}
U_{\text {randem }}=[(k+1) F(95 ; k+1, \\
n-k-1)]^{1 / 2} s\left(T_{h}\right) .
\end{gathered}
$$

The constant $F(95 ; k+1, n-k-1)$ is the upper 95 percentile of Snedecor's $F$-distribution with $k+1$ degrees of freedom in the numerator and $n-k-1$ degrees of freedom in the denominator, and $s\left(T_{k}\right)$ is the standard deviation of the predicted value, $T_{h}$. This uncertainty, based on the Working-Hoetelling confidence bands for the calibration curve, is valid for all future applications of the calibration curve as long as the model holds [15]. The details of the statistical analysis can be found in Ref. $[15,16]$. A software package, OMNITAB [17], is used for the statistical computations.

Data for the least-squares analysis of the $\mathrm{BB}$ are shown in Table 5. Temperature as measured by PRT sensor 1 is used as the independent variable, $X$. The analysis confirms that a linear function $(k=1)$ is sufficient for describing the data, and the following equation

$$
T_{h}=a_{0}^{\prime}+a_{1}^{\prime}\left(X_{h}\right)
$$

gives the predicted radiance temperature $\left(T_{h}\right)$ for a blackbody temperature $\left(X_{h}\right)$ measured by PRT 
Table 5. Data for the least-squares analysis of the BB

\begin{tabular}{|c|c|c|c|c|}
\hline $\begin{array}{l}\text { Nominal } \\
\text { (K) }\end{array}$ & $\begin{array}{c}\text { Sensor } 1 \\
(\mathbf{K}) \\
X\end{array}$ & $\begin{array}{l}\text { Radiance } \\
\text { temperature } \\
\text { (K) } \\
T\end{array}$ & $\begin{array}{l}\text { Standard } \\
\text { deviation } \\
(\mathrm{K}) \\
s\end{array}$ & $\begin{array}{l}\text { Weight } \\
\text { W }\end{array}$ \\
\hline \multirow[t]{3}{*}{200} & 199.897 & 201.427 & 3500 & 0.0798 \\
\hline & $199.874^{\prime \prime}$ & 201.539 & 1.420 & $0.49 \$ 7$ \\
\hline & 199.947 & 200.546 & 2.130 & 0.2203 \\
\hline \multirow[t]{3}{*}{225} & 224.780 & 225.736 & 2.990 & 0.1116 \\
\hline & 224.728 & 225.666 & 1.384 & 0.5224 \\
\hline & 224.823 & 225.5016 & 1.975 & 0.2564 \\
\hline \multirow[t]{3}{*}{250} & 249.662 & 250.135 & 2.100 & 0.2278 \\
\hline & 249.639 & 250.593 & 1.166 & 0.736 \\
\hline & 249.733 & 250,463 & 1.865 & 0.2875 \\
\hline \multirow[t]{3}{*}{275} & 274.6849 & 275.575 & 1.102 & 0.8239 \\
\hline & 274.644 & 275,466 & 1319 & 0.5751 \\
\hline & 274.719 & 275.605 & 1.101 & 0.8244 \\
\hline \multirow[t]{3}{*}{300} & 299.5309 & 300.683 & 0.715 & 1.9545 \\
\hline & 2995211 & 300.462 & 1.135 & 0.7760 \\
\hline & 299.588 & 300.683 & 0.887 & 1.2702 \\
\hline \multirow[t]{3}{*}{325} & $324.412^{\prime}$ & 326.342 & 0.830 & 1.4529 \\
\hline & 324.457 & 325.600 & 0.603 & 27502 \\
\hline & 324.446 & 325.658 & 1.076 & 0.8641 \\
\hline \multirow[t]{3}{*}{350} & 349.306 & 350.931 & 0.644 & 2.4084 \\
\hline & 349337 & 350.657 & 0.997 & 1.0056 \\
\hline & 349.445 & 350.807 & 0.869 & 1.3233 \\
\hline \multirow[t]{3}{*}{375} & $374.047^{a}$ & $376.500^{\circ}$ & 0.660 & 2.2930 \\
\hline & 374.069 & 375.766 & 0.816 & 1.5003 \\
\hline & 374.171 & 375.915 & 1.467 & 0.4647 \\
\hline \multirow[t]{3}{*}{400} & 399.026 & 401.171 & 0.872 & 1.3164 \\
\hline & 399.056 & 400.366 & 1.266 & 0.6242 \\
\hline & 399.131 & 401.240 & 1.217 & 0.6748 \\
\hline
\end{tabular}

- Data with standartized residuals from the finear fit exceeding 2.5 . These nutlick are not included in the final analysis.

sensor 1 . The estimated coefficients and associated standard deviations are:

$$
\begin{aligned}
& a_{0}^{\prime}=-1.096 ; s\left(a_{0}^{\prime}\right)=0.244 \\
& a_{l}^{\prime}=1.007 ; s\left(a_{1}^{\prime}\right)=0.001 .
\end{aligned}
$$

The percentage uncertainty in the deduced radjance temperature, $\delta T T$, is given by Eq. (1) and the theory of uncertainty propagation [18]. An approximation on a Taylor series expression gives the relationship between the variables as

$$
\delta T / T \sim \delta P / 4 P+\delta r_{i} / 2 r_{i}+\delta r_{2} / 2 r_{2}+\delta S / 2 S .
$$

The first term on the right hand side of Eq. (11) shows the relationship to the contribution from the uncertainty in the radiant power which has both Type A and Type B components as discussed above. The last three terms in Eq. (11) show the relationship to the contributions from the uncertainties in the measurement of the geometrical quantities, $r_{\text {, }}$, $r_{2}$, and $S$. A summary of the percentage uncertainties in the geometrical measurements (Table 2) and their propagated uncertainties for radiance temperature measurements are given in Table 6.

The predicted NIST radiance temperature from the calibration equation for each average value of temperature measured by PRT sensor 1 is given in Table 7 for the BB caljbration. The uncertainty 
Table 6. Uncertaintics in the measurements of geometrical quantitics for the BB

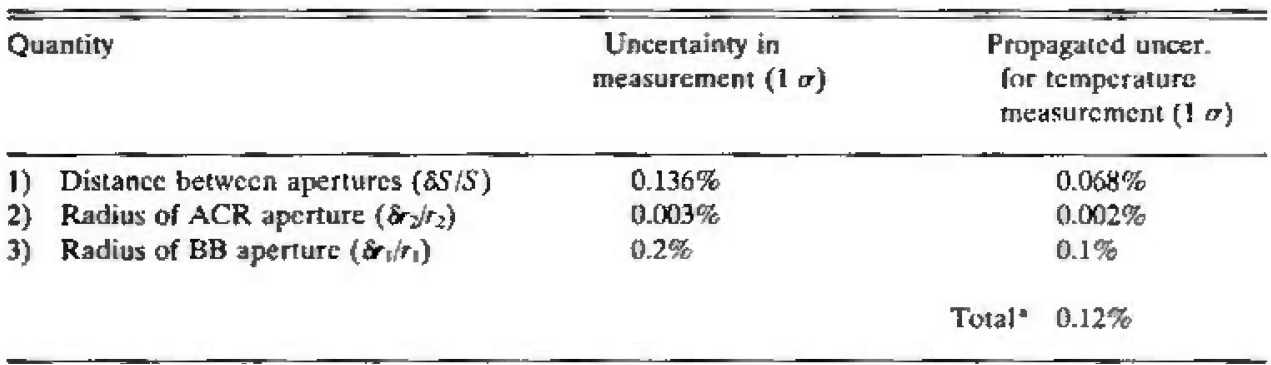

- Square root of sum of squares of 1,2 , and 3 given above.

Table 7. Predicted radiance temperatures and uncertaintics for $B \mathrm{~B}$

\begin{tabular}{|c|c|c|c|c|c|c|c|c|}
\hline \multirow[t]{2}{*}{ Nominal } & \multirow{2}{*}{$\begin{array}{l}\text { Sensor } 1 \\
\text { data } \\
\text { (K) }\end{array}$} & \multirow{2}{*}{$\begin{array}{l}\text { Predicted } \\
\text { radjance } \\
\text { termp } \\
\text { (K) }\end{array}$} & \multirow{2}{*}{$\begin{array}{l}\text { ACR } \\
\text { char } \\
\text { (K) }\end{array}$} & \multicolumn{3}{|c|}{ Systematic uncertaintics } & \multirow{2}{*}{$\begin{array}{c}1 \sigma \text { random } \\
\text { uncertainties } \\
\text { (K) }\end{array}$} & \multirow{2}{*}{$\begin{array}{c}\text { Expanded } \\
\text { uncer. (U) } \\
\text { (K) }\end{array}$} \\
\hline & & & & $\begin{array}{l}\text { Geometry } \\
\text { meas. } \\
\text { (K) }\end{array}$ & $\begin{array}{l}\text { Diff. } \\
\text { cal. } \\
\text { (k) }\end{array}$ & $\begin{array}{c}\text { Total } \\
b \\
(\mathrm{~K})\end{array}$ & & \\
\hline 200 & 199.906 & 2003 & 0.06 & 0.24 & 0.07 & 0.25 & 0.10 & $0.7(0.4 \%)$ \\
\hline 250 & 224.777 & 225.4 & 0.07 & 0.26 & 0.07 & 0.28 & 0.08 & $0.7(0.3 \%)$ \\
\hline 250 & 249.678 & 250.4 & 0.08 & 0.30 & 0.08 & 0.32 & 0.07 & $0.7(0.3 \%)$ \\
\hline 275 & 274.683 & 275.6 & 0.09 & 0.33 & 0.05 & 0.35 & 0.05 & $0.8(0.3 \%)$ \\
\hline 300 & 299.547 & 300.7 & 0.09 & 0.36 & 0.06 & 0.38 & $0.0 \mathrm{~A}$ & $0.8(0.3 \%)$ \\
\hline 325 & 324.429 & 325.8 & 0.10 & 0.39 & 0.07 & 0.41 & 0.04 & $0.8(0.3 \%)$ \\
\hline 350 & 349.362 & 350.9 & 0.11 & 0.42 & 0.07 & 0.44 & 0.04 & $0.9(0.3 \%)$ \\
\hline 375 & 374.120 & 375.8 & 0.11 & 0.45 & 0.08 & 0.47 & 0.05 & $1.0(0.3 \%)$ \\
\hline 400 & 399,071 & 400.9 & 0.12 & 0.48 & 0.08 & 0.5 & 0.07 & $1.0(0.3 \%)$ \\
\hline
\end{tabular}

components due to systematic effects are listed separately based on Eq. (11): 1) the uncertainty in the power $\delta P / 4 P$, due to the characterization of the ACR as an absolute detector [1] is listed in column $4 ; 2$ ) the uncertainty in defining the geometry as given in Table 6 is shown in column 5 ; and 3 ) the uncertainty in diffraction calculations due to approximations is shown in column 6 . The total systematic component, $\mathrm{b}$, which is the root sum of squares, is given in column 7. The Type A component, $s\left(T_{h}\right)$, of the uncertainty is obtained from least-squares analysis, and the expanded uncertainty, $U$, as shown in column 9 , is obtained by expanding Eq. (9) as follows [19]:

$$
\begin{gathered}
U=[(k+1) F(95 ; k+1, n-k-1)]^{t / 2} \\
{\left[s^{2}\left(T_{k}\right)+b^{2}\right]^{1 / 2} .}
\end{gathered}
$$

The multiplying factor in $\mathrm{Eq}$. (12) for $n=27, k=1$ for the $\mathrm{BB}$ experimental data is 2.6 . The value shown in parenthesis in column 9 is the expanded uncertainty given as a percentage of the measured temperature.

The statistical procedure that leads to Eq. (12) did not take into account possible correlations between Type $B$ uncertainties because of the relationship between varjables shown in Eq. (11). However, calculations of expanded uncertainty, $U$, using the complete covariance matrix and least square fitting using appropriate weights have been carried out and the results are found to be the same as given by Eq. (12). The calibration constants in Eq. (10) also are found to be essentially same as reported earlier.

Figure 3 shows the temperature value from PRT sensor 1 plotted on the $X$-axis and the measured radiance temperatures (Table 5) and corresponding 
predicted radiance temperature (Table 7) on the $Y$-axis. The solid line in Fig. 3 connects the predicted radiance temperature values and represents Eq. (10). Figure 4 shows the $95 \%$ confidence band for the difference between the calibrated temperature and the PRT temperature. The expanded uncertainty given in Table 7 is within $0.5 \%$.

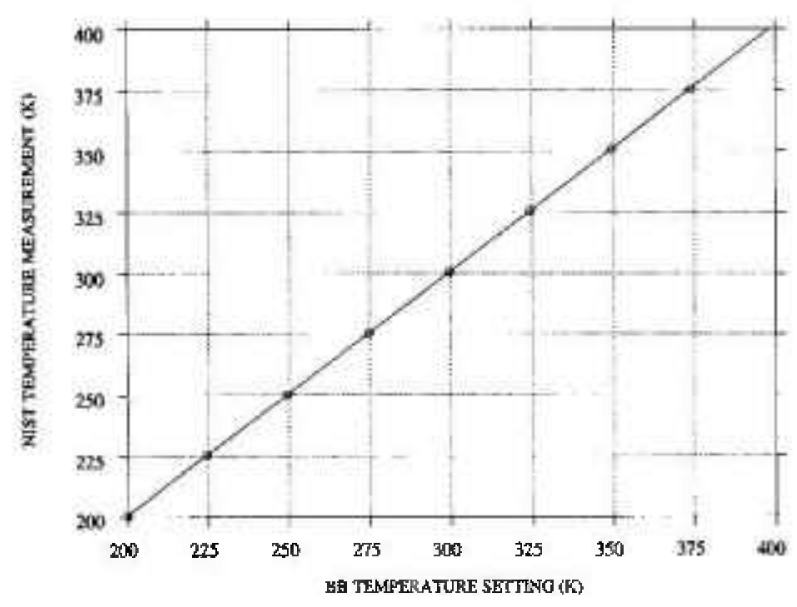

Fig. 3. Measured temperatures and calibrated radiance temperature from polynomial fit plotted as a furction of blackbody temperature setting using PRT sensor 1.

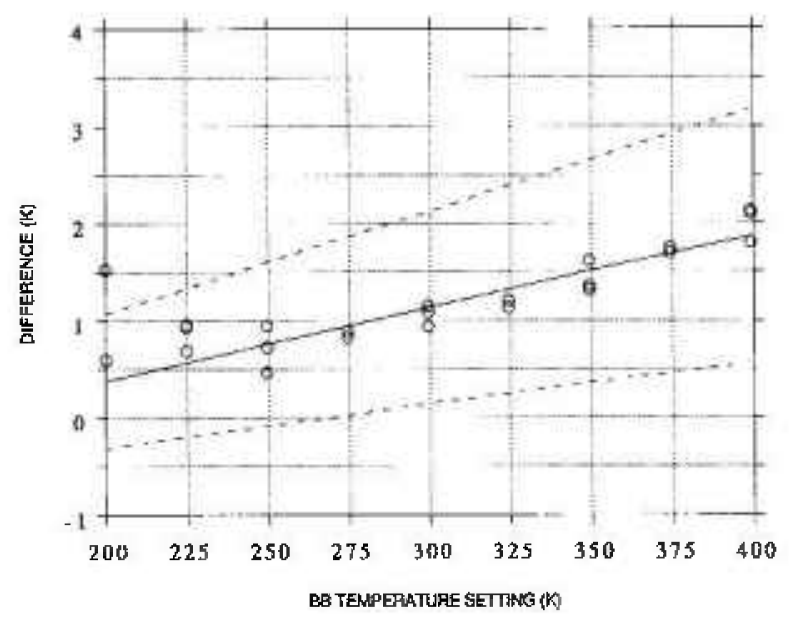

Fig. 4. Solid line: Difference between the deduced radiance temperature and the temperature measured by the blackbody PRT sensor 1 plotted as a function of blackbody temperature setting. The points represent the same for measured radiance temperatures and afe not all of equal weights. Dashed lines: Upper and lower bounds of $95 \%$ confidence bands.

However, it is always an open question why for example, at the nominal blackbody temperature of the $400 \mathrm{~K}$ does the temperature sensor 1 measure $399.071 \mathrm{~K}$ whereas the radiance temperature is
$400.9 \mathrm{~K}$ as shown in Table 7. The calibration curve does not address the effects of systematic errors such as unaccounted scattered light entering the ACR, aperture warming of the blackbody etc. However, experimental designs to eliminate such systematic effects are planned and implemented within the time allotted for customer calibrations. The experimental checks show these effects should be negligible. For future calibrations, spectral instrumentation is also being added to address this question further by measuring the emittance from the blackbody as a function of wavelength between $2 \mu \mathrm{m}$ to $30 \mu \mathrm{m}$ and comparing it with the currently assumed value of unity.

\section{Summary}

The LBIR facility is in operation for customer blackbody calibrations using the ACR as the absolute detector. The experimental procedure and analysis of data that generate the calibration report for the customer are described in detail, and a recent blackbody calibration at the facility serves as an example of the procedure. Calibration uncertainties in radiance temperatures of less than $1 \%$ have been realized for typical flux levels of $25 \mathrm{nW}$ and above at the ACR aperture. Experimental procedures to reduce systematic uncertainties are continuously investigated and implemented to improve the accuracy of measurements. Future improvements of noise control in the ACR operation could allow measurements down to $10 \mathrm{nW}$ at the ACR aperture with $1 \%$ uncertainty. Capability for measuring spectral emittance of customer sources in the 2 to 30 micrometer wavelength region is being developed.

\section{Acknowledgments}

The authors are indebted to S. Ebner and J. Proctor of NIST for their efficient operation of the LBIR instrumentation. We are also indebted to C. C. Hoyt and P. Miller of CRI, Inc., for giving effective training on the ACR operation.

About the authors: Dr. Raju Datla, a physicist, is the group leader of the IR Radiometry Group of the Radiometric Physics Division at NIST. Ms. Carroll Croarkin is a statistician in the Statistical Engineering Division at NIST. Dr. Albert Part, a physicist, is the Chief of the Radiometric Physics Division at NIST. The National Institute of Standards and Technology is an agency of the Technology Administration, U.S. Department of Commerce. 


\section{Disclaimer}

References made in this paper to particular brand names or specific suppliers of a service are made for ease of understanding by the reader and do not constitute an endorsement of products or service by the National Institute of Standards and Technology over other competitive suppliers of similar products or service.

\section{References}

[1] R. U. Datla, K. Stock, A. C. Par, C. C. Hoyt, P. J. Miller, and P. V. Foukal, Chancterization of an Ahsolute Cryogenic Radioneter as a Standard Detector for Radiant Power Measuremenis, Appl. Opt. 31. 7219 (1992).

[2] IIT Rescarch Instilute, 10 West 35th Street, Chicago, IL. 60616.

[3] S. C. Emmer, A. C. Parr, C. C. Hoyt, Imaging Infrared: Secne Simulation, Modelling, and Real Image Tracking; SPIE 1110, 49 (1989).

[4] Kaman Instruments Corporation, 1500 Garden of the Gnds Road, Colurado Springs; CO 80933-7463.

[5] C. L Wyatt, Radiometric System Design, MacMillan, NY, (1987) pp. 37-38.

[6] A. F Clark, Thermal Expansion, Chapter 3 in Mater iats at Low Tcmperatures, P. R Rced and A. F. Clark, cds., American Society for Metals (1983) p. 95.

[7) W. H. Stecl, M. De, J. A. Bell, Diffraction Contections in Radiometry. J. Opt. Soc. Amer. 62, 1099 (1972).

[8] L. P. Boivin, Diftraction Corrections in the Radiometry of Extended Snurces, Appl. Opt. 15, 1204 (1976).

[9] ISO Guide to the Expression of Uncertainty in Masurement, prepared hy ISO Technical Advisory Growp 4 (TAG 4), Working Group 3 (WO 3 ) 1993.

[10] J. Neter, W. Wasserman, and M. H. Kutnee, Applied Lin: ear Statistical Models, Sec. Ed.. Richard D. Irwin, Inc, Homewond, IL 60430 (1985) P. 539.

[11] B. N. Taylor and C. E Kuyat, Guidelines for Evatuating and Expressing the Uncertainty of NIST" Measurement Results, NIST Technical Note 1297 (1993).

[12] Eiscnhart, C, Precision Measurement and Calibration: Slatistical Concepts and Procedures, H. H. Ku, ed., NBS Spccial Publication 300, Vol. I (1969).

[13] N. Draper and H. Sinith. Applied Regression Analysis, Second Ed., Wilcy \& Sons, NY (1981) pp. 10 og-116.

[14] Reference [10] pp. 109-122.

[15] Reference [10] p. 154.

[16] M. G. Natrelia, Experimental Statistics, John Wiley, NY (1966) ch. 5.

[17] S. T. Peavy, S. G. Bremcr, R. N. Vatner, and D. Mngber, OMNITAB 80: An Interpretive System for Statistical and Numerical Data Analysis, NBS Special Publication 701 (1986).

[18] H. H. Ku, Notes on the use of Propagation of Error Forumulas, Precision Mcaşurement and Calibration: Statistical Concepts and Procedures, H. H. Ku, ed, NBS Spect. Publ. 300, Vol. I (1969).

[19] K. Eberhardt, Staff menber of NIST Stat istical Enginecring Division, (Private Communication). 